\title{
A review on the performance of reinforced concrete structures under blast loading
}

\author{
K. Senthil ${ }^{* 1 \text { iD }}$, Iwansh Gupta ${ }^{\text {iD }}$, S. Rupali ${ }^{1}$ (D), Loizos Pelecanos ${ }^{2}$ iD \\ ${ }^{1}$ Dr. B R Ambedkar National Institute of Technology, Department of Civil Engineering, Punjab, India \\ ${ }^{2}$ University of Bath, Department of Architecture and Civil Engineering, Bath, United Kingdom
}

\begin{abstract}
An explosion on the elevated structures caused by terrorist activities or manmade events can induce significant deformations in the Civil Engineering structures. Therefore, it is necessary to review the response of the structural behavior such as reinforced concrete slab, reinforced concrete beams, and columns. On the basis of this objective, a detailed literature review is conducted to understand the scope for protecting such structures and the structural behavior under blast loading. Based on the detailed literature survey, the investigations about the behavior of conventional reinforced concrete columns and slab initiated in 2005 however, the behavior of reinforced concrete beam was focused since the year 2010. Also, the literature reveals that the investigations on structural elements using analytical techniques are limited in comparison to experiments and simulations. In addition to that, the response of the structural elements was predicted and the trend was calibrated and fitted logarithmically with the experimental results. The predicted spall diameter in the reinforced concrete slab is $0.95 \mathrm{~m}$ corresponding charge weight of $100 \mathrm{~kg}$ however the influence of spalling was found to be negligible after the $100 \mathrm{~kg}$ of charge weight. The predicted spall length in the reinforced concrete beam is $1.6 \mathrm{~m}$ corresponding charge weight of $100 \mathrm{~kg}$ and the effect may be negligible after $100 \mathrm{~kg}$ of charge weight. The predicted deflection in the reinforced concrete columns is $30 \mathrm{~mm}$ corresponding to a peak reflected impulse of $1000 \mathrm{MPa}-\mathrm{ms}$, whereas the deflection was found to be negligible after the $1000 \mathrm{MPa}-\mathrm{ms}$ of peak reflected impulse.
\end{abstract}

\section{Keywords}

Structural elements; Experiment; Simulations; Analytical studies; Review

Received: 27 October 2020; Accepted: 29 November 2020

ISSN: 2630-5763 (online) C 2020 Golden Light Publishing All rights reserved.

\section{Introduction}

Terrorism played a wide role in the life of civilians as well as important infrastructures through the use of explosions for the last few decades. Due to the increase of terrorist attacks over the past few decades the effect of blast loads on the structure is a serious matter of concern that should be taken into consideration in the design process. There are few studies were conducted in the past to predict the behavior of structural elements such as slabs, columns, and beams against blast loading. However, there is a shortfall of data due to the complex nature of the experiment that helps in designing the structural elements against blast loading. Therefore, the present review study is focused to predict the behavior of structural elements through simple techniques using the experimental data available in the literature. The

* Corresponding author

Email: urssenthil85@yahoo.co.in 
protection of infrastructures like hospitals, power stations, dams, nuclear facilities, tunnels against blast loading is of critical importance to the nation. The pattern of the blast loading is different as the peak pressures are of higher magnitudes however their durations are short in comparison with the natural periods of the structures. Based on the latest published article published in 2019 and 2020 [1-7], it was observed that the structural elements are too sensitive to the blast loading.

The blast loading is more impulsive than dynamic loading which sometimes leads to the partial collapse of structure and structural elements. The Engineers as well as consultants are expected to enhance the response of buildings in the context of blasts or any other extreme vulnerabilities. For analyzing building against blast loading, a sophisticated approach like developing numerical techniques, analytical methods, and experimental investigations are important. In the past, researchers have published various research articles based on the use of experimental, analytical as well as numerical methods on structural systems like reinforced concrete columns, beams, and slabs. This review paper highlights the importance of structural elements against blast loading and the contributions addressed by the researchers in this field which is of utmost importance in the present scenario. The response of reinforced concrete slab against blast loading is discussed in Section 2 . Similarly, the response of reinforced concrete beams and columns against blast loading is discussed in Sections 3 and 4, respectively. At last, the generalized as well as technical conclusions are drawn based on the detailed review are presented in Section 5.

\section{Responses in reinforced concrete slabs}

The response of reinforced concrete slab against blast loading has been reviewed in light of experiments, simulations as well as analytical solutions. Further, the importance of these investigations and the grey area in light of the present scenario is addressed.

\subsection{Literature on the experimental studies}

$\mathrm{Xu}$ and $\mathrm{Lu}$ [8] revealed three quantity-distance regimes through the experimental results. In the "small" quantity regime, the critical standoff distance is also small, subsequently, the effect is a localized phenomenon in the "intermediate" quantity regime, the spallation appears to be dimension sensitive. The "large" regime is dominated by global failure along the boundary lines. Wang et al. [9-10] found that the peak pressure is increasing by reducing the standoff distance of charge weight on RC slab subjected to blast loading. Thiagarajan et al [11] suggested that the high-strength concrete was very effective in reducing the level of response under blast loading. Due to blast loading, the propagation of cracks is on the surface of the reinforced concrete slab, without being very sensitive to mesh sizes. Foglar et al. [12] found that the waste steel fibers added into the concrete mixture had a minimal effect on the blast performance of FRC. Yao et al [13], Zhao and Chen [14] state that the increase of explosive charge is shown to gradually change the damage degree of RC slab from inelastic deformation to local spallation failure. While with the increase of reinforcement ratio, the damage degree, deflection, and the spall radius were all decreasing.

Alengaram et al. [15] observed the ductility of oil palm shell concrete OPSC, it exhibited multiple cracks and is still able to absorb energy and it is potential impact-resistant material. The mild steel plates resulted in the highest residual plate deformations whereas the high-strength steel reduced in the peak deformation compared to the mild steel plates. Remennikov et al. [16] computed different RC slabs under non-uniform blast loading. Meng et al. [17] found that the novel green construction material, high-performance alkaliactivated geopolymer concrete slab combining the steel wire mesh reinforcement helps in increasing the blast resistance capacity. Based on the literature, it has been observed that the spall radius in the concrete slab is influenced by the charge weight, see Table 1 however the information about the behavior of the slab was found to be limited and the study requires detailed investigations. 
Table 1. Response of slab under varying charge weight

\begin{tabular}{lcc}
\hline Literature & $\begin{array}{c}\text { Charge } \\
\text { weight }(\mathrm{kg})\end{array}$ & $\begin{array}{c}\text { Spall radius } \\
(\mathrm{mm})\end{array}$ \\
\hline Wang et al. [19] & 0.13 & 50 \\
Zhao and Chen [14] & 0.31 & 90 \\
Olmati et al. [23] & 0.40 & 102 \\
Wang et al. [19] & 0.64 & 120 \\
Wang et al. [19] & 0.94 & 185 \\
\hline
\end{tabular}

Schenker et al. [18] stated that the concrete slab response to the blast wave load revealed a complex behavior of spring back due to insufficient restrain of the slab edge to the heavy Wolfman support. Wang et al. [19] found that when the initial shock wave generated by the blast passes through the concrete slab and is reflected off the free surface, the shock wave is converted into a tensile wave, resulting in a high level of cracking in the concrete because of its low tensile strength and the spallation was found to occur on the bottom of the slab. Mao et al. [20] observed that with the increase of fiber volume in Ultra high-performance fiber-reinforced concrete slab, the deflection in the slab is decreasing therefore, it indicates the increased blast resistance of UHPFRC slab. Kristoffersen et al. [21] found that the strains and the damage in the concrete slabs were reduced in the analysis when steel-bar reinforcement was included against the blast loading. Based on the results available in the literature, the response of slab in terms of spall radius corresponding to various charge weights is shown in Fig. 1(a). The trend was calibrated by trend line options available in Excel such as exponential, linear, logarithmic, varying degrees of polynomials, power, and moving average. It was observed that the data logarithmically fitted very well with the experimental results however, all the options available in the MS Excel were tried and found that those options were not signifying the results. Further, the response of reinforced concrete slab was predicted against varying the charge weight, see Fig. 1(b). The expected spall diameter in the reinforced concrete slab is $0.95 \mathrm{~m}$ corresponding charge weight of $100 \mathrm{~kg}$ however the influence of spalling may be negligible after the 100 $\mathrm{kg}$ of charge weight. The $\mathrm{R}^{2}$ value was found to be 0.89 to fit with experimental results.

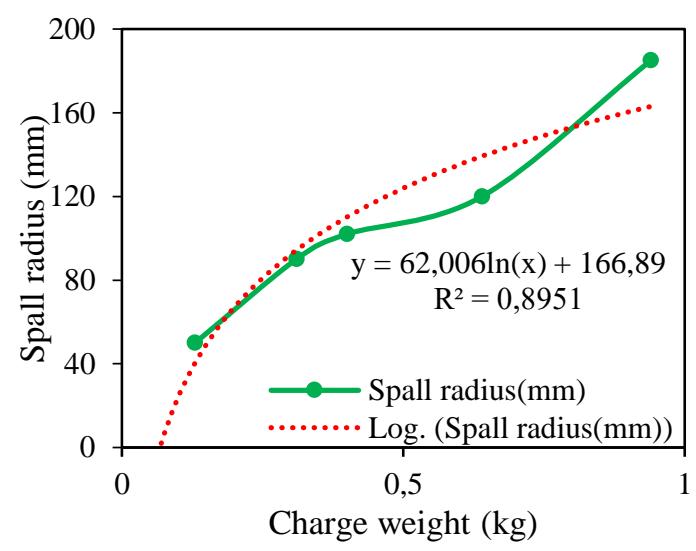

(a) Experiment

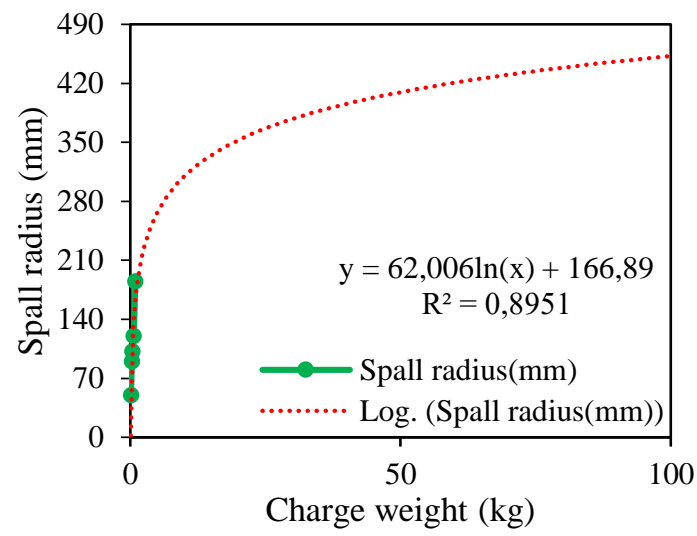

(b) Project as logarithmic from the experimental study

Fig. 1. Spallation of concrete against varying charge weight

The damage intensity was identified as a high fragmentation zone, less fragmentation zone, and very less fragmentation zone, see Fig. 2. However, the fragmentation area may vary depends on the configuration of the slab, the grade of concrete, and level of reinforcement as well as charge weight.

\subsection{Literature on the numerical studies}

The damage may occur at the slab center if the concrete slab reinforcement ratio is very low whereas, as the reinforcement ratio is increased, the slab deformation is reduced and damage may occur at the support or shear failure may occur at the center point [22]. 


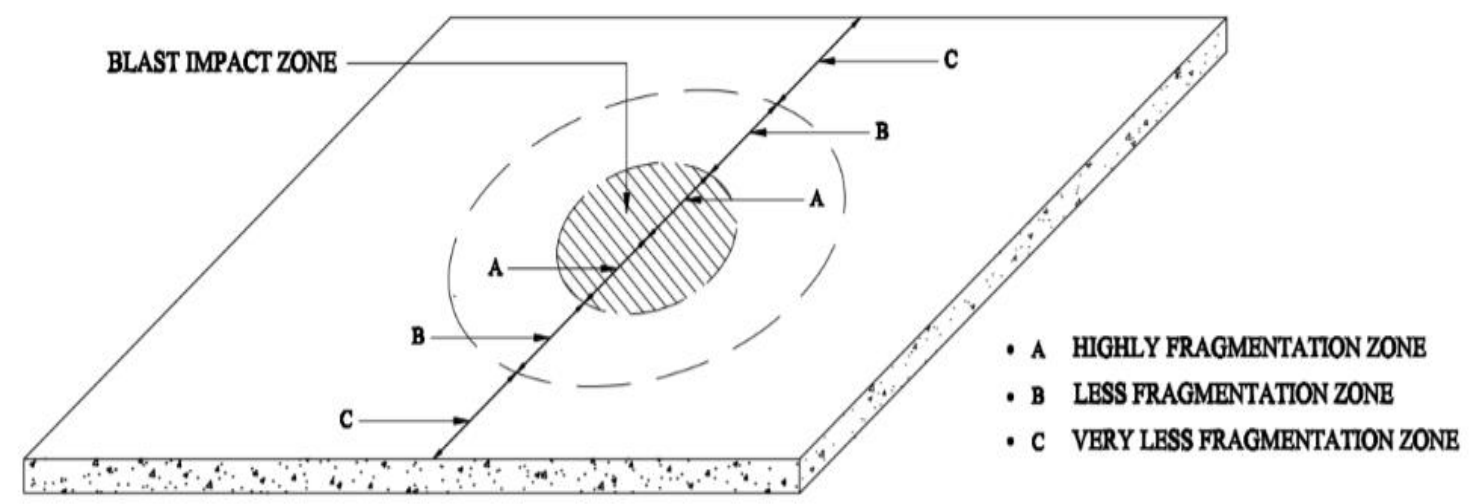

Fig. 2. Location of fragmentation of slab

Olmati et al. [23] stated that several factors such as boundary conditions, the complexity of material properties available, material models used, and finite element parameters such as element type selection, mesh size sensitivity, material model rate effects amongst others contribute to the prediction of the response of a structure when subjected to shock/blast loading. The concrete spalling and crushing were found to be important damage modes under blast loading and this phenomenon was prominent when the explosives were detonated close to or in contact with concrete structures [24]. The response of reinforced concrete slab using numerical analysis in terms of deflection, vonMises stresses, compression, and tension damage of concrete and found that on increasing the charge weight the deflection was also increasing $[25,26]$.

The concrete strength, slab thickness, and reinforcement ratio may influence the behavior of $\mathrm{RC}$ slabs to resist blast loading [27]. Jiaming $\mathrm{Xu}$ and Yong $\mathrm{Lu}$ [28] stated that the former leads to an effective break-up of the slab along the shear failure line, while the latter eventually results in the reinforcing bars being pulled through in the concrete, which effectively eliminates the reinforcement effect and causes the collapse of the slab. Haokai et al. [29] observed that the damage degree is directly affected by the explosive weights and positions. Also, it was observed that when the explosive weight is increased or the explosive standoff distance is decreased, the damage degree would increase.

\subsection{Literature on the analytical studies}

This study proposed that increasing the thickness of the slab and percentage of steel reinforcement, and reducing the slab rigidity by changing its supported conditions, all have a positive effect on the performance of the flexural response of RC slab against blast loading [30]. It is proposed that energy dissipated through the spallation of concrete can be quantified by the ratio of the total surface area over the total fragmented volume [31]. The mean peak reflected pressures at every scaled distance obtained by $\mathrm{Wu}$ et al. [31], an equation of the peak reflected pressure, in $\mathrm{kPa}$, to the scaled distance as

$P_{r_{\text {max }}}=\frac{139.97}{Z}+\frac{844.81}{Z^{2}}+\frac{2154}{Z^{3}}-0.8034$

The peak pressure and the duration of an explosion are normally related to the scaled distance, $Z$ (in $\mathrm{m} / \mathrm{kg}^{1 / 3}$, where $Z=R / W^{1 / 3}, R$ and $W$ are respectively the distance from charge center in $\mathrm{m}$ and the equivalent TNT charge weight in $\mathrm{kg}$ ). Colombo and Martinelli [33] observed that the ratio of diameter to length is less than 4 , the combined effect of shear and bending failure should be taken into account in the analysis. Kadid et al. [32] observed that the slab dimensions are an important parameter and it has to be considered when designing reinforced concrete slabs against blast loading therefore slabs having one dimension much larger than the other have better behavior than that of slabs having close dimensions in the two directions. The pressure time-history has been approximated by the following exponential form: 
$P[t]=P_{0}+P_{S}^{+}\left[1-\frac{t}{T^{+}}\right] e^{-b t / T^{+}}$

in the positive phase, maximum overpressure, $\mathrm{P}_{\mathrm{s}}^{+}$, is developed instantaneously and decays to atmospheric pressure, $P_{0}$, in the time, $T^{4}$, see Fig. 3.

\section{Response in reinforced concrete beams}

The response of reinforced concrete beams against blast loading have been reviewed in light of experiments, simulations as well as analytical solutions. Further, the importance of these investigations and the grey area in light of the present scenario is addressed.

\subsection{Literature on the experimental studies}

It was suggested that the effect of the strain rate on a beam should be incorporated more accurately in SDOF analysis by which higher accuracy and better agreement governed with the experimental results [34]. The local damage degree of RC beams with the smaller size has been reduced a little as compared with that of beams with the larger size. The reinforced concrete beam bending quickly under the impact of an explosive blast wave [35]. The tensile stress wave reflected from the free bottom surface of the beam forms two kinds of vertical cracks (tensile cracks and compressive cracks). The reason for the main crack propagation, the transversal expansion resulting from Poisson's effect leads to the exfoliation of the side-cover concrete [36]. The beam before blast loading suffers more severe spallation in the direction of depth due to the flexural shear stresses [37]. The varying scale distance of the charge weight leads toward the changes in damage mode of the beam [38]. Based on the detailed literature, the spall length in the reinforced concrete beam is influenced by the charge weight, see Table 2 however the information about the behavior of the beam was found to be limited and the study requires detailed investigations.

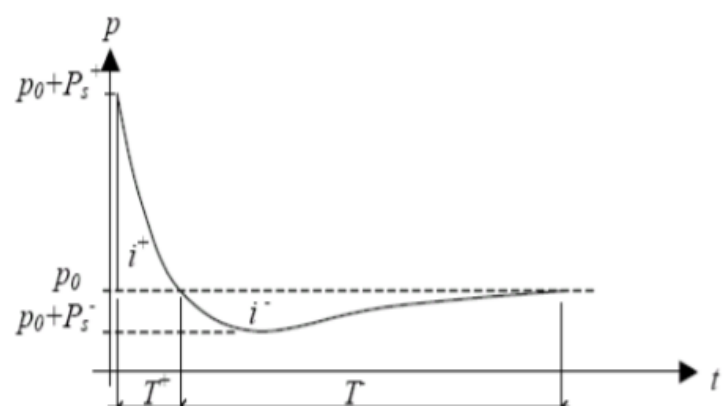

Fig 3. Pressure- time history from a blast (exponential form)

Table 2 Response of slab under varying charge weight

\begin{tabular}{lcc}
\hline Literature & $\begin{array}{c}\text { Charge } \\
\text { weight }(\mathrm{kg})\end{array}$ & $\begin{array}{c}\text { Spall length } \\
(\mathrm{mm})\end{array}$ \\
\hline Yan et al. [36] & 0.5 & 120 \\
Zhang et al. [35] & 0.7 & 150 \\
Liu et al. [38] & 0.85 & 315 \\
Liu et al. [38] & 1.1 & 318 \\
\hline
\end{tabular}

The pre-stressing RC beams increase their blast loading resistance capacities if the failure is governed by flexural responses, however, it may reduce the blast loading resistance capacities if the failure is governed by the shear response. However, increasing the pre-stress level in the beam may increase the diagonal shear damage near the beam supports, the blast resistance performance of the pre-stressed beam might be a disadvantage [39]. The higher enhancement of the structural performance of RC beams was obtained when a higher amount of steel fibers were incorporated. The crack profiles revealed that the shear crack inclinations increased with an increase in the number of steel fibers and strain rate [40].

The effective length of the beam is related to the rate of applied loading, wave speed, and cracking of the beam subjected to the blast loading [41]. Based on the literature, the investigation on the behavior of reinforced concrete beams was studied however the information about the behavior was found limited and needs detailed investigation. The response of beams in terms of spall length corresponding to various charge weights is shown in Fig. 4(a). The trend was calibrated by trend line 
options such as exponential, linear, logarithmic, varying degrees of polynomials, power, and moving average and logarithmic was fitted with the experimental results. Further, the response of the reinforced concrete beam was predicted against varying the charge weight, see Fig. 4(b). The expected spall length is $1.6 \mathrm{~m}$ corresponding charge weight is $100 \mathrm{~kg}$ and the influence of spalling may be negligible after the $100 \mathrm{~kg}$ of charge weight. The $\mathrm{R}^{2}$ value was found to be 0.809 to fit with experimental results.

The damage intensity was identified as the initial position, deflection, and spall length, see Fig. 5. The spallation length may vary depends on the configuration of the beam, grade of concrete and reinforcement as well as charge weight.

\subsection{Literature on the numerical studies}

The simulations may not be able to reliably predict the localized failure of structures [42]. The cracks starting from the bottom of the beam are developed which are caused by flexural failure therefore, it

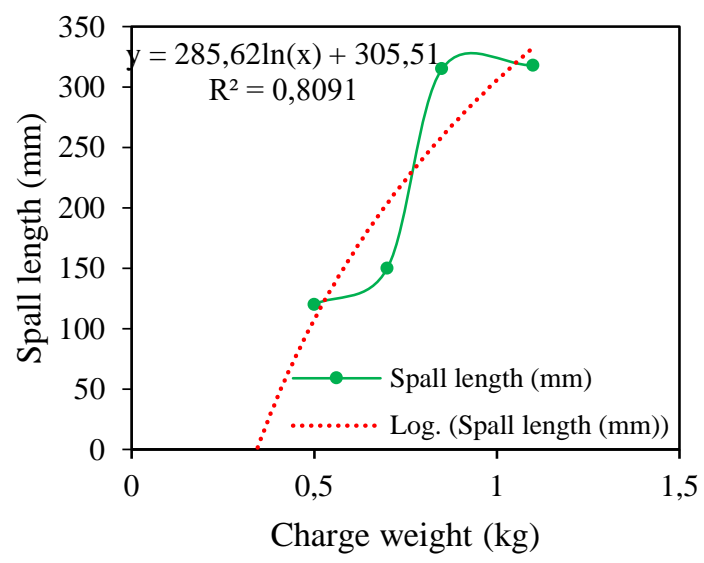

(a) experiment states that the damage modes of RC beams against impact loading is flexural failure [43]. The profiles of displacement, rotation, and curvature along the length of the beam at the time of detonation, may not be correctly determined [44]. The initial cracks on the surface of the compression zone have a larger influence than that on the surface of the tensile zone under the blast loading [45]. The percentage of collapse in a beam is related to the peak load and slenderness ratio therefore, a rough measure of the reliability of the beam under blast loading can be estimated [46].

\subsection{Literature on the analytical studies}

The reliability of a beam depends not only on the slenderness ratio as well as from span length. The maximum displacement was decreasing with increasing span length and with decreasing slenderness ratio. With the constant geometry and boundary condition, a short span beam is less reliable than a long span beam [47].

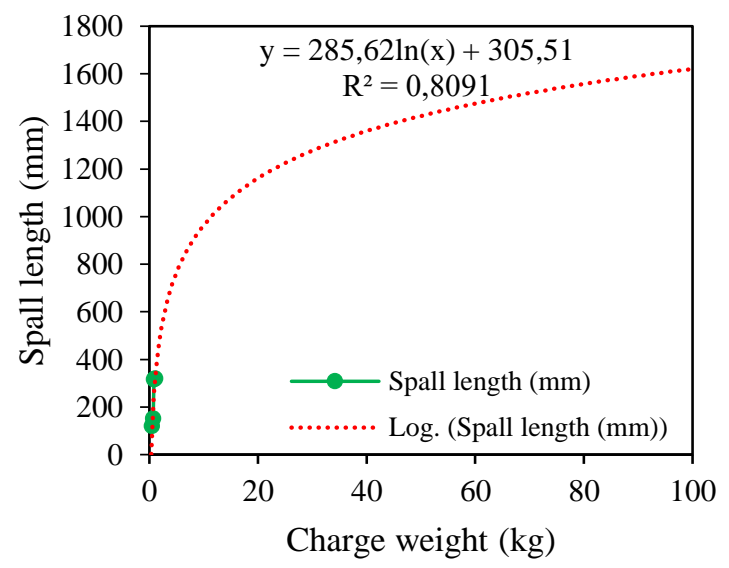

(b) projection as logarithmic from the present study

Fig. 4. Spallation of concrete against varying charge weight

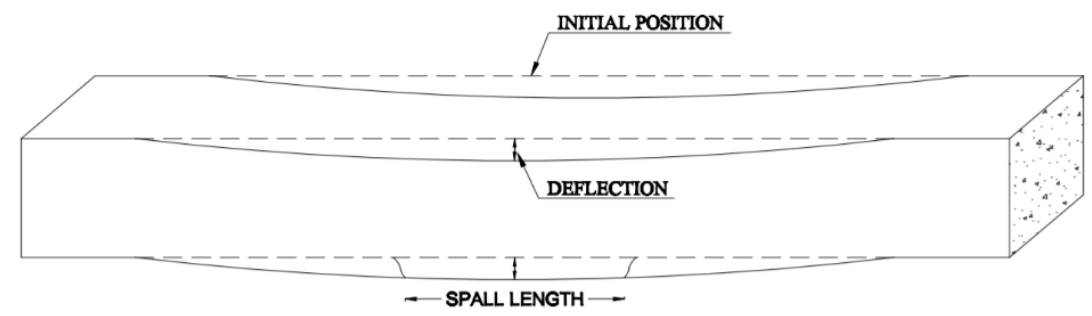

Fig. 5. Deflection and spallation of reinforced concrete beams 
The extent of damage increases with the decrease in the value of cracking strain thus indicating that the cracking strain is a sensitive parameter in the analysis of impact loading [48]. Hamra et al [49] observed that the lateral restraint and mass indirectly affect the behavior of the beam against blast loading. Therefore, it is concluded that the mechanical and geometrical properties are directly affected by the behavior of the beam against blast loading. The loading is assumed to develop synchronously along the beam and is idealized as a triangular pulse, see Fig. 6, so that

$P(x, t)=P_{0}\left[1-\frac{t}{t_{d}}\right]$

where $t$ represents the time variable, $\mathrm{P}_{\mathrm{o}}$ is the peak blast pressure and $t_{d}$ is the positive phase duration.

Sungsoo and Liviu [50] found that the induced strain localization in the beam by blast loading change the dynamic response of the structures. Lellep and Torn [51] observed that the shear sliding for the deformation is more essential in shorter span beams as compared to the longer span beam against the blast loading, Ulrika Nystro and Kent Gylltof [52] observed that the impulse from the blast was almost 2.5 times the impulse caused by the fragments, therefore, the damage caused by combined loading is more severe. Li et al. [53] observed that the elastic shear stiffness has a significant influence on the maximum transverse shear displacement and the critical impulsive velocity. The shear failure of the beam under blast loading becomes more likely if the elastic shear stiffness of the beam is large.

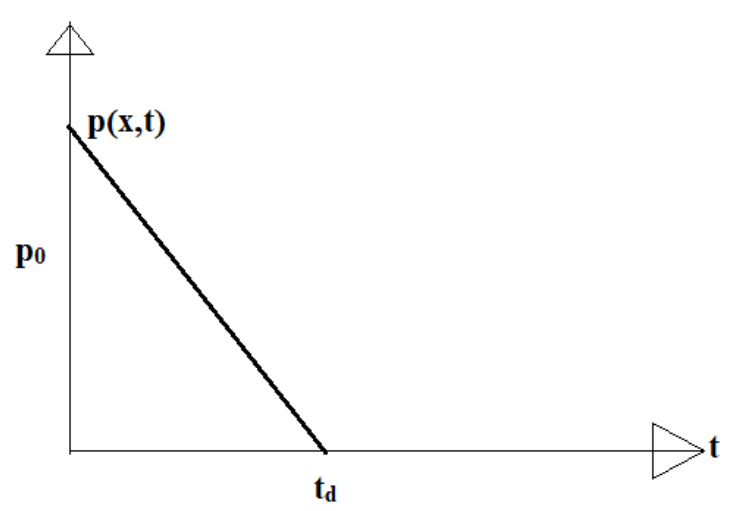

Fig. 6. Idealized blast loading

\section{Responses in reinforced concrete columns}

The response of reinforced concrete columns against blast loading has been reviewed in light of experiments, simulations as well as analytical solutions. Further, the importance of these investigations and the grey area in light of the present scenario is addressed.

\subsection{Literature on the experimental studies}

The effect of axial load ratio is more critical in the case of columns with a low transverse reinforcement ratio [54]. It is observed that the use of fibers with optimized properties (increased aspect-ratio and tensile strength) led to improvements in the blast performance of the UHPFRC columns, with reductions in maximum displacement against the blast loading [55]. Li and Hao [56] concluded that spall damage is relatively insensitive to the column height, however, it depends on column depth and reinforcement mesh. Also, it was observed that increasing column depth and reinforcement confinement is very effective in mitigating concrete spall damage. Mazurkiewicz et al. [57] proposed that not only the mass of the detonated charge has an influence on the structural behavior, however, its shape and the initiation point of detonation, which can significantly change the extent of the structural damage. Zhang and Zhao [58] stated that the increase in explosive charge weight caused a larger mid-span deflection, with this effect being more noticeable on axial-load-free specimens rather than axially-loaded specimens. Based on the literature, the spall length in the reinforced concrete beam is influenced by the charge weight, see Table 3 however the information about the behavior of the beam was found to be limited and the study requires detailed investigations.

Based on the literature, the investigation on the behavior of reinforced concrete columns was studied however the information about the behavior was found to be limited and need a detailed investigation. The response of columns in terms of deflection corresponding peak reflected impulse is shown in Fig. 7(a). 
Table 3. Peak reflected impulse corresponding maximum deflection

\begin{tabular}{lcc}
\hline Literature & $\begin{array}{c}\text { Peak reflected } \\
\text { impulse } \\
\text { (MPa-ms) }\end{array}$ & $\begin{array}{c}\text { Maximum } \\
\text { deflection }\end{array}$ \\
\hline Aoude et al. [55] & 0.381 & 29.9 \\
Shi et al. [69] & 0.900 & 36 \\
Zhang et al. [58] & 3.070 & 41 \\
Zhang et al. [58] & 4.200 & 49 \\
\hline
\end{tabular}

The trend was calibrated by trend line options available in Excel such as exponential, linear, logarithmic, varying degrees of polynomials, power, and moving average, however, logarithmic was fitted with the experimental results. Further, the response of the reinforced concrete column was predicted against varying the peak reflected impulse, see Fig. 7(b). The expected deflection is $30 \mathrm{~mm}$ the corresponding peak reflected impulse $1000 \mathrm{MPa}-\mathrm{ms}$ whereas the influence of deflection may be negligible after the $1000 \mathrm{MPa}-\mathrm{ms}$ of peak reflected impulse. The deflection was predicted corresponding $\mathrm{R}^{2}$ value was 0.92 .

The generalized damage pattern was identified based on the detailed literature survey, see Fig. 8. The spallation length may vary depending on the configuration of columns, the grade of concrete and reinforcement as well as charge weight.

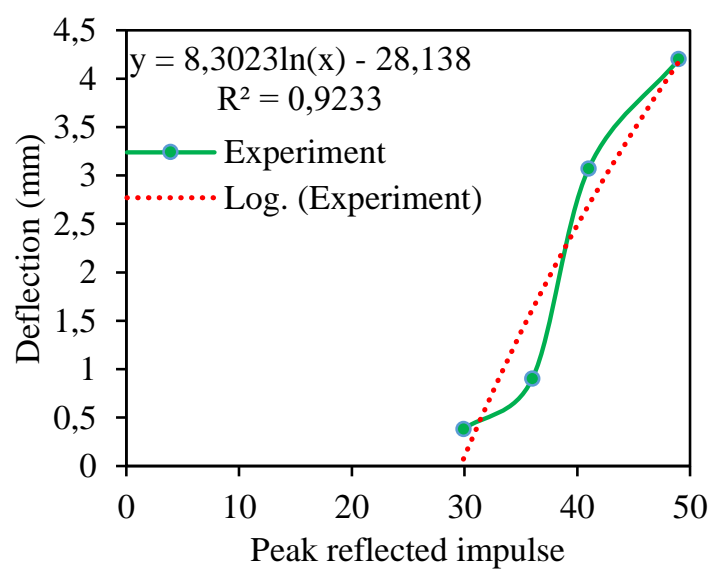

(a) experiment

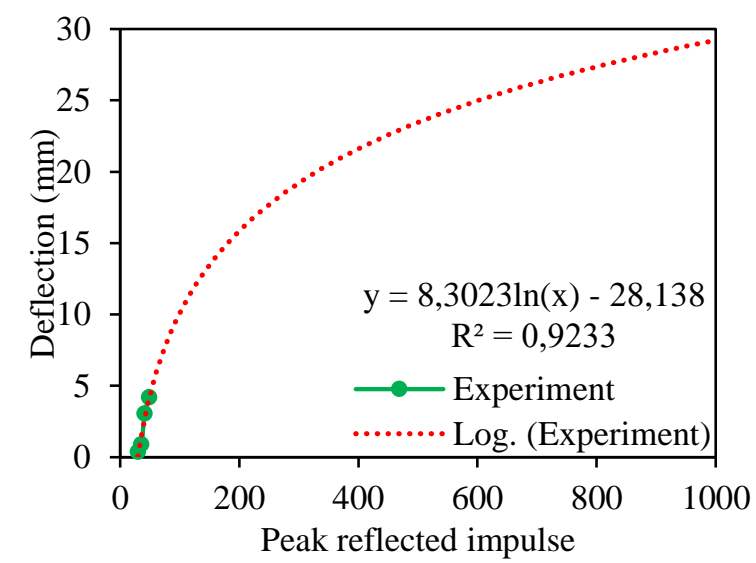

(b) projection as logarithmic from the present study

Fig. 7. Peak reflected impulse versus maximum deflection

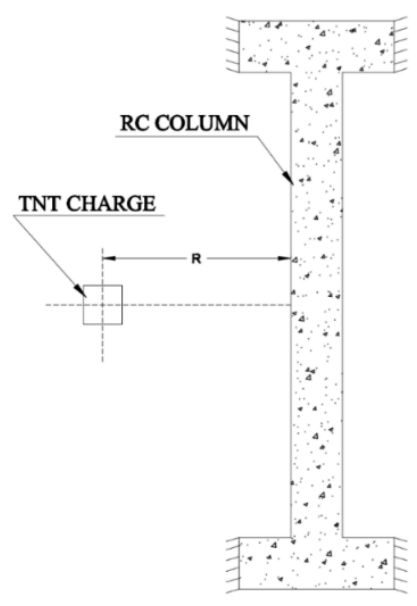

(a) before

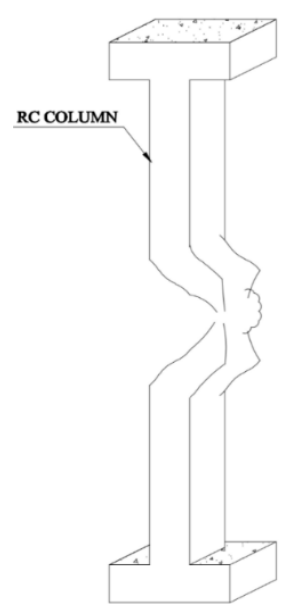

(b) after detonation

Fig. 8. Deflection and spallation of reinforced concrete column 


\subsection{Literature on the numerical studies}

The bending moments revealed the generation of the third mode of vibration in the impacted column and generation of maximum shear forces at contraflexure points close to the supports [59]. The maximum lateral deflection experienced by the column decreased exponentially with the increase in the stand-off distance and also deflection is decreased in the case of the columns were strengthened [60]. The deflected shapes of axially loaded members under blast loading may be approximated by the elastic deflected shape under uniform static loading in the elastic range, and under dynamic loading in the plastic range[61]. Astarlioglu et al. $[62,63]$ observed that the blast loads with very high peak pressures, the columns were prone to direct shear-type failures. Shi and Stewart [64] concluded that structural reliability is based on the structural response, damage, and collapse risks for reinforced concrete columns subjected to an explosion. The load-carrying capacity of damaged columns reduces significantly as the stand-off distance increasing against explosives. Abladey and Braimah [65] observed that the deflection of the reinforced concrete column is increasing with the increase of charge mass at a constant standoff distance. The deflection of the column is smaller when columns having closely spaced transverse reinforcement subjected to the blast loading. Echevarria et al. [66]. The resistance offered by the column leads towards the damage in a column against the blast loading, Kravchenko et al. [67] also found that the steel ratio has a considerable effect on the column resistance to the blast impact. The dynamics of the column fracture demonstrates the work of the crosswise binders with a fracture in the load application area. Thai and Kim [68] stated that the slender column shows both local and global failures whereas the axial compressive loads in the range of $0.1 \mathrm{fc}^{\prime} \mathrm{Ag}$ $0.4 \mathrm{fc}^{\prime} \mathrm{Ag}$ were found to have a significant effect on increasing the damage level of the slender column.

\subsection{Literature on the analytical studies}

The initial reflected pressure may be quickly relieved at the edge of the column, and the column will be engulfed with the blast wave due to diffraction [69, 70]. A careful examination of the pressure-impulse curves finds that they can be expressed analytically as

$\left(P-P_{0}\right)\left(I-I_{0}\right)=A\left(\frac{P_{0}}{2}+\frac{I_{0}}{2}\right)^{\beta}$

where $\mathrm{P}_{0}$ is the pressure asymptote, $\mathrm{I}_{0}$ is the impulsive asymptote and $\mathrm{A}$ and $\beta$ are constants. Based on the literature, it has been observed that the investigation of the behavior of reinforced concrete columns was studied in the last two decades however the information about the behavior was found to be limited and needs a detailed investigation.

\section{Conclusions}

Based on the detailed literature survey on the response of reinforced concrete elements such as slabs, beams, and columns against blast loading, the following generalized conclusions were drawn:

- In light of a detailed literature review, the investigations about the behavior of conventional reinforced concrete columns and slabs were started from the year 2005, however, the behavior of reinforced concrete beams was focused from 2010 onwards.

- However, the investigations on structural elements using analytical techniques were found to be limited in comparison to experiments and simulations.

- Owing to the literature survey and is evident that the research on blast loading and the effect it has on the structural element is very limited and needs to be attended keeping in mind the present scenario and the terror threat.

Along with the generalized conclusions, the following specific conclusions were drawn based on detailed literature and predictions:

- The predicted spall diameter in the reinforced concrete slab is $0.95 \mathrm{~m}$ corresponding charge weight of $100 \mathrm{~kg}$ however the influence of spalling was found to be negligible after the 100 $\mathrm{kg}$ of charge weight. The $\mathrm{R}^{2}$ value was 0.89 to fit with the experimental results. 
- The predicted spall length in the reinforced concrete beam is $1.6 \mathrm{~m}$ corresponding charge weight of $100 \mathrm{~kg}$ and the effect may be negligible after $100 \mathrm{~kg}$ of charge weight. The $\mathrm{R}^{2}$ value was 0.809 to fit with the experimental results.

- The predicted deflection in the reinforced concrete columns is $30 \mathrm{~mm}$ corresponding to a peak reflected impulse of $1000 \mathrm{MPa}-\mathrm{ms}$ with $\mathrm{R}^{2}$ of 0.92 whereas the effect is negligible after the $1000 \mathrm{MPa}-\mathrm{ms}$ of peak reflected impulse.

- Based on the detailed literature review, it was observed that the structural elements are too sensitive to the blast loading. Therefore, it is concluded that the detailed numerical investigations and few basic experiments are most important to estimate the resistance of the structural elements.

\section{Declaration of conflicting interests}

The author(s) declared no potential conflicts of interest concerning the research, authorship, and/or publication of this article.

\section{References}

[1] Rishabh J, Maiti PR (2019) Transient effect of blast loads on RCC building. The Asian Review of Civil Engineering 8(1): 9-19.

[2] Almustafa MK, Nehdi ML (2020) Machine learning model for predicting structural response of RC slabs exposed to blast loading. Engineering Structures 221: 111109.

[3] Viet-Chinh M, Ngoc-Quang V, Van-Tu N, Hoang P (2020) Ultra-high-performance fiber reinforced concrete panel subjected to severe blast loading. Defence Science Journal 70(6): 603-611.

[4] Mali DP, Mulay SB (2020) Impact of blast loading on building. Journal of Interdisciplinary Cycle Research 12(4): 839-844.

[5] Nuhu1 SM, Kaura JM, Lawan A, Shuaibu AA (2020) Probabilistic analysis of reinforced concrete slab subjected to blast loading. Journal of Science Technology and Education 8(4): 99-111.

[6] Wu J, Zhou Y, Zhang R, Liu C, Zhang Z (2020) Numerical simulation of reinforced concrete slab subjected to blast loading and the structural damage assessment, Engineering Failure Analysis 118: 104926.
[7] Shukla PJ, Desai AK, Modhera CD (2021) Dynamic response of cut and cover tunnel section under blast loading. Innovative Infrastructure Solutions 6, Article number: 27.

[8] Xu K, Lu Y (2006) Numerical simulation study of spallation in reinforced concrete plates subjected to blast loading. Computers \& Structures 84: 431-438.

[9] Wang W, Zhang D, Lu F, Wang SC, Tang F (2012) Experimental study on scaling the explosion resistance of a one-way square reinforced concrete slab under a close-in blast loading. International Journal of Impact Engineering 49: 158-164.

[10] Wang W, Zhang D, Lu F, Wang SC (2012) A new non-uniform blast load model for SDOF method of one-way reinforced concrete slab. EPJ Web of Conferences 26: 04016.

[11] Thiagarajan G, Kadambi AV, Robert S, Johnson CF (2015) Experimental and finite element analysis of doubly reinforced concrete slabs subjected to blast loads. International Journal of Impact Engineering 75: 162-173.

[12] Marek F, Hajek R, Kovar M, Štolle J (2015) Blast performance of RC panels with waste steel fibers. Construction and Building Materials 94: 536-546.

[13] Yao S, Zhang D, Chen X, Lu F, Wang W (2016) Experimental and numerical study on the dynamic response of RC slabs under blast loading. Engineering Failure Analysis 66: 120-129.

[14] Zhao CF, Chen JY (2013) Damage mechanism and mode of square reinforced concrete slab subjected to blast loading. Theoretical and Applied Fracture Mechanics 63: 54-62.

[15] Alengaram UJ, Mohottige NHW, Wu C, Jumaat MZ, Poh YS, Wang Z (2016) Response of oil palm shell concrete slabs subjected to quasi-static and blast loads. Construction and Building Materials 116: 391-402.

[16] Remennikov A, Ngo T, Mohotti D, Uy B, Netherton M (2017) Experimental investigation and simplified modelling of response of steel plates subjected to close-in blast loading from spherical liquid explosive charges. International Journal of Impact Engineering 101: 78-89.

[17] Meng Q, Wu C, Su Y, Li J, Liu J, Pang J (2019) A study of steel wire mesh reinforced high performance geopolymer concrete slabs under blast loading. Journal of cleaner production 210: 11501163.

[18] Schenker A, Anteby I, Gal E, Kivity Y, Nizri E, Sadot O, Ben-Dor G (2008) Full-scale field tests of concrete slabs subjected to blast loads. 
International Journal of Impact Engineering 35(3): 184-198.

[19] Wang W, Zhang D, Lu F, Wang SC, Tang F (2012) Experimental study and numerical simulation of the damage mode of a square reinforced concrete slab under close-in explosion. Engineering Failure Analysis 27: 41-51.

[20] Mao L, Barnett SJ, Tyas A, Warren J, Schleyer GK, Zaini SS (2015) Response of small scale ultra-high performance fibre reinforced concrete slabs to blast loading. Construction and Building Materials 93: 822-830.

[21] Kristoffersen M, Pettersen JE, Aune V, Børvik T (2018) Experimental and numerical studies on the structural response of normal strength concrete slabs subjected to blast loading. Engineering Structures 174: 242-255.

[22] Tai YS, Chu TL, Hu HT, Wu JY (2011) Dynamic response of a reinforced concrete slab subjected to air blast load. Theoretical and Applied Fracture Mechanics 56: 140-147.

[23] Olmati P, Trasborg P, Naito C, Sgambi L, Bontempi F (2016) Modeling the response of concrete slabs under blast loading. American Concrete Institute - Symposium paper, 306: 5.15.20 .

[24] Li J, Wu C, Hao H, Wang Z, Su Y (2016) Experimental investigation of ultra-highperformance concrete slabs under contact explosions. International Journal of Impact Engineering 93: 62-75.

[25] Singhal A, Senthil K, Shailja B. Influence of boundary condition and mass of TNT on the behaviour of concrete slab under blast loading. Proceedings on the National Conference of Advanced Structures, Materials and Methodology in Civil Engineering, 2018, Jalandhar, India.

[26] Senthil K, Singhal A, Shailja (2019) Damage mechanism and stress response of reinforced concrete slab under blast loading. Coupled Systems Mechanics 84: 315-338.

[27] Du H, Li Z (2009) Numerical analysis of dynamic behavior of RC slabs under blast loading. Transactions of Tianjin University 15(1): 61-64.

[28] Xu J, Lu YA (2013) Comparative study of modelling RC slab response to blast loading with two typical concrete material models. International Journal of Protective Structures 4(3): 415-432.

[29] Jia H, Yu L, Wu G (2014) Damage assessment of two-way bending RC slabs subjected to blast loadings. The Scientific World Journal 12: 718702.
[30] Low HY, Hao H (2001) Reliability analysis of reinforced concrete slabs under explosive loading. Structural Safety 23(2): 157-178.

[31] Wu C, Nurwidayati R, Oehlers DJ (2009) Fragmentation from spallation of RC slabs due to airblast loads. International Journal of Impact Engineering 36(12): 1371-1376.

[32] Kadid A, Nezzar B, Yahiaoui D (2012) Nonlinear dynamic analysis of reinforced concrete slabs subjected to blast loading. Asian Journal of Civil Engineering (Building and Housing) 13(5): 617634.

[33] Colombo M, Martinelli P (2011) SDOF models for RC and FRC circular plates under blast loads. Applied Mechanics and Materials, Trans Tech Publications 82: 440-445.

[34] Nassr AA, Razaqpur AG, Tait MJ, Campidelli M, Foo S. (2011) Experimental performance of steel beams under blast loading. Journal of Perform of Constructed and Facilities 26: 600-619.

[35] Zhang D, Yao SJ, Lu FY, Chen XG, Lin GH, Wang W, Lin YL (2013) Experimental study on scaling of RC beams under close-in blast loading. Engineering Failure Analysis 33: 497-504.

[36] Yan B, Liu F, Song DY, Jiang ZG (2015) Numerical study on damage mechanism of RC beams under close-in blast loading. Engineering Failure Analysis 51: 9-19.

[37] Yao SJ, Zhang D, Lu FY, Wang W, Chen XG (2016) Damage features and dynamic response of RC beams under blast. Engineering Failure Analysis 62: 103-111.

[38] Liu Y, Yan JB, Huang F (2018) Behavior of reinforced concrete beams and columns subjected to blast loading. Defense Technology 14: 550-559.

[39] Chen W, Hao H, Chen S (2015) Numerical analysis of prestressed reinforced concrete beam subjected to blast loading. Materials \& Design 65: 662-674.

[40] Lee JY, Shin HO, Yoo DY, Yoon YS (2018) Structural response of steel-fiber-reinforced concrete beams under various loading rates. Engineering Structures 156: 271-283.

[41] Cotsovos DM, Stathopoulos ND, Zeris CA (2008) Behavior of RC beams subjected to high rates of concentrated loading. Journal of structural engineering 134(12): 1839-1851.

[42] Li J. Hao H (2011) Development of a simplified numerical method for structural response analysis to blast load. Procedia Engineering 14: 2558-2566. 
[43] Jiang H, Wang X, He S (2012) Numerical simulation of impact tests on reinforced concrete beams. Materials \& Design 39: 111-120.

[44] Carta G, Stochino F (2013) Theoretical models to predict the flexural failure of reinforced concrete beams under blast loads. Engineering Structures 49: 306-315.

[45] Qu Y, Li X, Kong X, Zhang W, Wang X (2016) Numerical simulation on dynamic behavior of reinforced concrete beam with initial cracks subjected to air blast loading. Engineering Structures 128: 96-110.

[46] Stochino F (2016) RC beams under blast load: Reliability and sensitivity analysis. Engineering Failure Analysis 66: 544-565.

[47] Acito M, Stochino F, Tattoni S (2011) Structural response and reliability analysis of $\mathrm{RC}$ beam subjected to explosive loading. In Applied Mechanics and Materials 82: 434-439.

[48] Abbas H, Gupta NK, Alam M (2004) Nonlinear response of concrete beams and plates under impact loading. International Journal of Impact Engineering 30(8-9): 1039-1053.

[49] Hamra L, Demonceau JF, Denoël V (2015) Pressure-impulse diagram of a beam developing non-linear membrane action under blast loading. International Journal of Impact Engineering 86: 188-205.

[50] Na S, Librescu L (2000) Dynamic response of adaptive cantilevers carrying external stores and subjected to blast loading. Journal of Sound and Vibration 231(4): 1039-1055.

[51] Lellep J, Torn K (2005) Shear and bending response of a rigid-plastic beam subjected to impulsive loading. International journal of impact engineering 31(9): 1081-1105.

[52] Nyström U, Gylltoft K (2009) Numerical studies of the combined effects of blast and fragment loading. International Journal of Impact Engineering 36(8): 995-1005.

[53] Li QM, Ye ZQ, Ma GW, Jones N, Zhou HY (2009) The influence of elastic shear deformation on the transverse shear failure of a fully clamped beam subjected to idealized blast loading. International Journal of Mechanical Sciences 51(6): 413-423.

[54] Bao XL, Li B (2010) Residual strength of blast damaged reinforced concrete columns. International Journal of Impact Engineering 37: 295-308.

[55] Aoude H, Dagenais FP, Burrell RP, Saatcioglu M (2015) Behaviour of ultra-high-performance fiber reinforced concrete columns under blast loading. International Journal of Impact Engineering 80: 185-202.

[56] Li J, Hao H (2014) Numerical and theoretical study of concrete spall damage under blast loads. In Applied Mechanics and Materials 553: 774-779.

[57] Mazurkiewicz L, Malachowski J, Baranowski P (2015) Blast loading influence on load carrying capacity of I-column. Engineering Structures 104: 107-115.

[58] Zhang F, Wu C, Zhao XL, Xiang H, Li ZX, Fang Q, Liu Z, Zhang Y, Heidarpour A, Packer JA (2016) Experimental study of CFDST columns infilled with UHPC under close-range blast loading. International Journal of Impact Engineering 93: 184-195.

[59] Thilakarathna HMI, Thambiratnam DP, Dhanasekar M, Perera N (2010) Numerical simulation of axially loaded concrete columns under transverse impact and vulnerability assessment. International Journal of Impact Engineering 37(11): 1100-1112.

[60] Elsanadedy HM, Almusallam TH, Abbas H, AlSalloum, YA, Alsayed SH (2011) Effect of blast loading on CFRP-retrofitted RC columns - a numerical study. Latin American Journal of Solids Structures 8: 55-81.

[61] Nassr AA, Razaqpur AG, Tait MJ, Campidelli M, Foo S (2013) Dynamic response of steel columns subjected to blast loading. Journal of Structural Engineering140: 04014036.

[62] Astarlioglu S, Krauthammer T, Morency D, Tran TP (2013) Behaviour of reinforced concrete columns under combined effects of axial and blastinduce transverse loads. Engineering Structures 55: 26-34.

[63] Astarlioglu S, Krauthammer T (2014) Response of normal-strength and ultra-high-performance fiberreinforced concrete columns to idealized blast loads. Engineering Structures 61: 1-12.

[64] Shi Y, Stewart MG (2015) Spatial reliability analysis of explosive blast load damage to reinforced concrete columns. Structural safety 53: 13-25.

[65] Abladey L, Braimah A (2014) Near-field explosion effects on the behaviour of reinforced concrete columns: a numerical investigation. International Journal of Protective Structures 5(4): 475-499.

[66] Echevarria A, Zaghi AE, Chiarito V, Christenson R, Woodson S (2015) Experimental comparison of the performance and residual capacity of CFFT and 
RC bridge columns subjected to blasts. Journal of Bridge Engineering 21: 04015026.

[67] Kravchenko G, Trufanova E, Kostenko D, Tsurikov S (2017) Analysis of blast load on a reinforced concrete column in the time domain. MATEC Web of Conferences 106: 04019.

[68] Thai DK, Kim SE (2018) Numerical investigation of the damage of RC members subjected to blast loading. Engineering Failure Analysis 92: 350-367.
[69] Shi Y, Hao H, Li ZX (2007) Numerical simulation of blast wave interaction with structure columns. Shock Waves 17: 113-133.

[70] Shi YC, Hao H, Li ZX (2008) Numerical derivation of pressure-impulse diagrams for prediction of $\mathrm{RC}$ column damage to blast loads. International Journal of Impact Engineering 35: 1213-1227. 